\title{
TOWARDS A COLLABORATIVE MODEL FOR WIRELESS SENSOR NETWORKS
}

\author{
Lina M. Pestana Leão de Brito, Laura M. Rodríguez Peralta \\ and Maurício D. Luís Reis \\ Laboratory for Usage-centered Software Engineering (LabUse), \\ Centro de Ciências Matemáticas (CCM), Mathematics and Engineering Department (DME) \\ University of Madeira (UMa), Campus da Penteada 9000-390 Funchal, Madeira, \\ PORTUGAL. \\ \{lina,lmrodrig,_m_reis\}@uma.pt \\ Collaboration is crucial to Wireless Sensor Networks (WSNs) as a result of \\ the typical resource limitations of wireless sensor nodes. In this paper, we \\ present a model of collaborative work for WSNs. This model is called Wireless \\ Sensor Networks Supported Cooperative Work (WSNSCW) and was created \\ for these specific networks. We also present the formalization of some entities \\ of the model and its properties. This is a generic model that is being used as a \\ basis for the development of a $3 D$ awareness tool for WSNs.
}

\section{Introduction}

A Wireless Sensor Network (WSN) consists of a large number of wireless sensor nodes that are, typically, densely deployed. These nodes collect data in the environment surrounding them. Then, data is sent to the user via a sink node, in a multi-hop basis (Alkyildiz et al., 2002).

Taking advantage of wireless communications, WSNs allow for a wide range of applications: environmental monitoring, surveillance, health, traffic monitoring, security, military, industry, agriculture, catastrophe monitoring, etc.

However, wireless sensor nodes are intended to be small and cheap. Consequently, these nodes are typically resource limited (limited battery, reduced memory and processing capabilities). Moreover, due to short transmission range, nodes can only communicate locally, with a certain number of local neighbours. Consequently, wireless sensor nodes have to collaborate in order to accomplish their tasks: sensing, signal processing, computing, routing, localization, security, etc. Thus, WSNs are, by nature, collaborative networks (Gracanin et al., 2006).

At the moment, there are several works regarding collaboration in WSNs, but they refer to a specific type of collaborative task. Until now, the only work that presents a model for cooperative work in sensor networks has been proposed by Liu et al. (2006). However, this model does not consider the particularities of WSNs.

In this paper, we present a model of cooperative work designed for the specific case of WSNs, named Wireless Sensor Networks Supported Cooperative Work 
(WSNSCW). So, it considers the specific requirements of WSNs. It allows not only for the modelling of collaborative work (based in CSCW concepts), but also for the modelling of all the entities that can constitute a WSN. This model is being used in the development of a 3D awareness tool for WSNs.

This paper is organized as follows. In section 2 , we briefly describe the related work. In section 3, the WSNSCW model is defined, formalized and exemplified. Section 4 provides some conclusions and perspectives of future work.

\section{Related Work}

Even though there are several works concerning collaboration in WSNs, they only focus a specific type of collaboration, which is associated with the accomplishment of a certain task, such as: sensing (Wang et al., 2005), signal processing (Ramanathan et al., 2002), computing (Iftode et al., 2004), routing (Chen et al., 2006), localization (Dardari et al., 2004), security (Chadha et al., 2005), task scheduling (Sanli et al., 2005), heuristics (Reghelin et al., 2006), calibration (Bychkovskiy et al., 2003), resource allocation (Giannecchini et al., 2004), time synchronization (Hu et al., 2005), transmission (Krohn et al., 2006), etc. Usually, these collaborations simply intend to improve some parameters of the network (energy cost, coverage, transmission cost, processing cost, delay, etc.).

There are also works regarding collaboration between wireless sensor nodes and other devices (heterogeneous groupware collaboration) to support some specific applications (for e.g., collaboration between sensor nodes and PDAs, in a fire fighting scenario (Cheng et al., 2004)).

The only work found in literature that presents a model for collaborative work in sensor networks, to date, has been proposed by Liu et al. (2006). It is the SNSCW (Sensor Networks Supported Cooperative Work) model. It is a hierarchical model that divides cooperation in sensor networks in two layers. The first one relates to cooperation between humans and sensor nodes (user-executor relationship, being initiated either by the user or by the sensor node), and the other layer relates to cooperation between the sensor nodes (considers two main subtypes of cooperation: peer-to-peer and master-to-slave).

This model was designed for sensor networks. However, it does not consider the specific requirements of WSNs, for instance: its scale, its self-configuration and self-maintenance requirements, the resource limitations of wireless sensor nodes, etc. Also, it only allows for modelling of collaboration itself.

\section{The WSNSCW Model}

In this section, we present a model of collaborative work for the specific case of WSNs, named Wireless Sensor Networks Supported Cooperative Work (WSNSCW). As WSNSCW is a model of collaborative work created specifically to WSNs, it considers the particular requirements of WSNs. It is, essentially, a graphbased model; nevertheless, it includes other objects in order to make the modelling 
of all the entities of a WSN possible, which is fundamental to completely represent a WSN.

The SNSCW model (Liu et al., 2006) only focuses the different types of cooperation that can occur in a WSN. Our model not only allows for the modelling of cooperation within the network, but also for the modelling of the entire WSN and all its entities (different types of nodes, relationships, base stations, clusters, etc.). Regarding collaboration, the model includes some fundamental CSCW (Computer Supported Cooperative Work) concepts and properties.

Moreover, WSNSCW is a generic model, in the sense that it can be applied to any type of wireless sensor nodes, regardless of its size, its hardware characteristics, the types of signals it can measure, etc. It can also be applied to any WSN despite of its specific application. However, in this paper we are going to illustrate the application of this model to the specific case of an environmental monitoring application.

\subsection{Definitions}

We define entities as all the components that might exist in a WSN. Table 1 shows the symbol, the concept and the description of all the entities included in the proposed model.

A WSN can have different types of nodes: ordinary wireless sensor nodes, anchor nodes (which support the sensor nodes in the localization process), one or more sink nodes (also known as base stations, which are responsible for sending data to the gateway) and a gateway (responsible for sending data to the user, through the Internet). If nodes are grouped in clusters, one of the members of each cluster becomes the cluster head. In this case, all nodes have to send data to the cluster head (usually, the most powerful node of the cluster), which, in turn, is responsible for sending data to a sink node.

If two nodes collaborate, a relationship is established between them. This relationship can be based on: localization of the nodes (proximity), common cluster, phenomenon to monitor, hardware characteristics of the sensor node, etc. Associated with a relationship there is always an exchange of data, which corresponds to the data flow entity. Collected data (temperature, humidity, light, etc.) can be sent to other nodes using one or more types of signals (radio, acoustical, etc.). Obstacles may obstruct the line-of-sight between nodes, influencing the relationships created.

Several collaborative sessions can be established when monitoring a WSN, and they can exist simultaneously or not. Basically, new sessions may be established based on new goals (type of phenomenon to monitor, geographical area to monitor, monitoring time, etc.).

As battery is the most critical resource of a sensor node, it is really important that the user knows the state of the battery of each node. Thus, the battery is also an entity of our model.

\subsection{WSNSCW Formalization}

Using both first-order logic and graph theory, we formalize the main properties of only some of the entities of the model: sensor node, network (WSN) and sink node. 
Table 1 - Definition of the entities can constitute a Wireless Sensor Network.

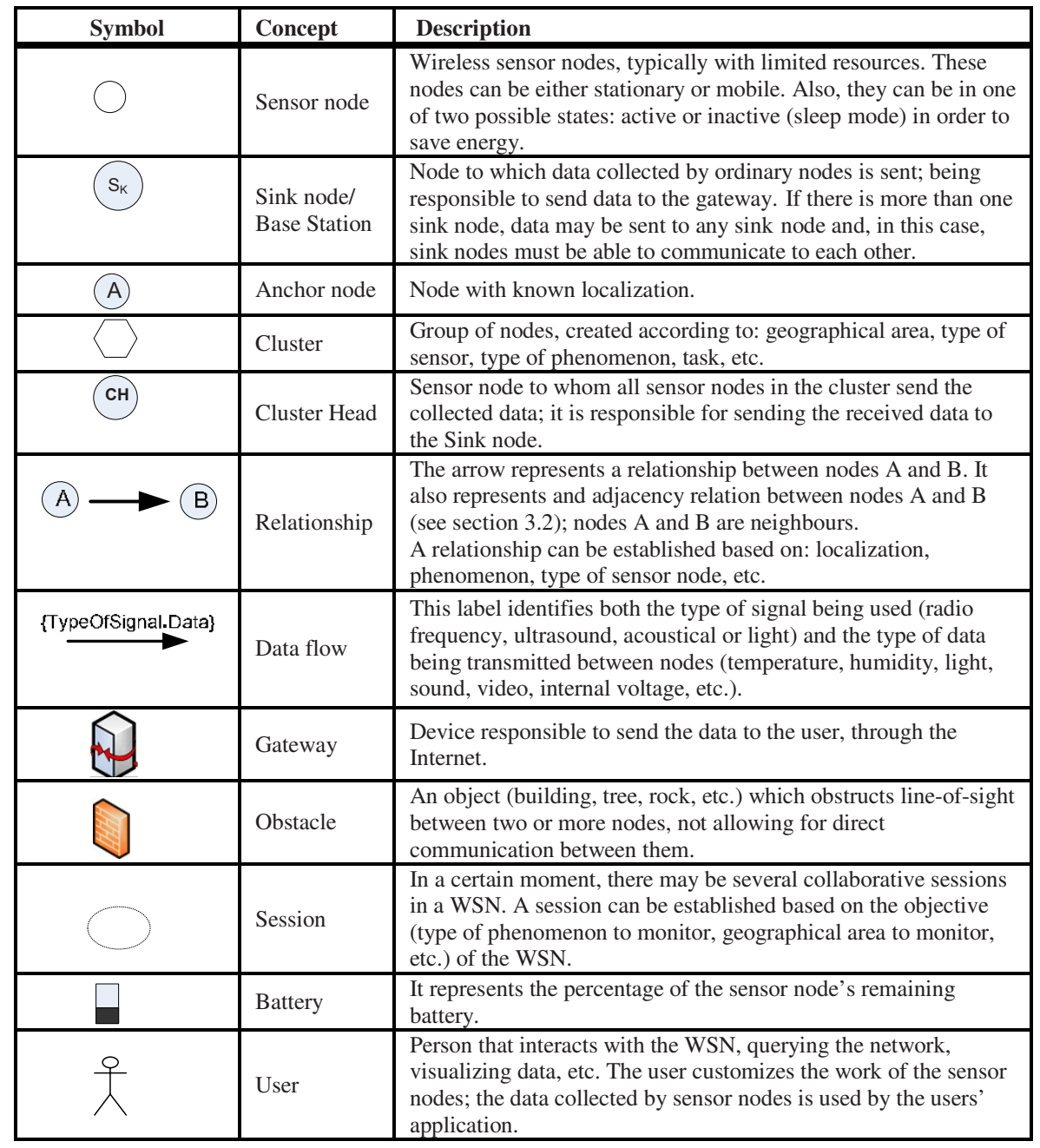

\section{Definitions}

We can formulate the sensor network as a graph $G(V, E)$. V (vertices) represents the set of sensor nodes, and $\mathrm{E}$ (edges) describes the adjacency relation between nodes. That is, for two nodes $\mathrm{u}, \mathrm{v} \in \mathrm{V},(\mathrm{u}, \mathrm{v}) \in \mathrm{E}$ if and only if $\mathrm{v}$ is adjacent to $\mathrm{u}$.

An arrow between two nodes represents a relationship between them. The arrow represents a producer-consumer relationship. Considering, for example, two nodes: $\mathrm{A}$ and $\mathrm{B}$; the arrow $\mathrm{A} \longrightarrow$ (B) means that node $\mathrm{A}$ transmits data to node B. So, node $\mathrm{B}$ consumes information from node $\mathrm{A}$. The transmission of data between both nodes follows the format TypeOfSignal.Data ( $\stackrel{\text { \{TypeofSignal.Data\} }}{\longrightarrow}$ ), verifying the consumerproducer property. 
Assuming $\mathrm{Nr}$ is the total number of sensor nodes that constitute the WSN, let $\mathcal{N}$ $=\{1,2, \ldots, \mathrm{Nr}\}$. Let's represent a wireless sensor node by $\mathrm{N}_{\mathrm{i}}$, with $\mathrm{i} \in \mathcal{N}$.

The WSN has a limited lifetime, which can vary from some hours to several months or years. Denoting by LT the lifetime of the network (in seconds), let $\mathcal{T}=\{1$, $2, \ldots, \mathrm{LT}\}$ and $\mathrm{t}_{\mathrm{j}}$ represent the $\mathrm{j}^{\text {th }}$ second of life of the network, with $\mathrm{j} \in \mathcal{T}$.

\section{Sensor Node $\left(N_{i}\right)$}

A sensor node $\left(\mathrm{N}_{\mathrm{i}}\right)$ is defined by: $\mathrm{N}_{\mathrm{i}}=\left\{\mathrm{TS}, \mathrm{CM}, \mathrm{R}, \mathrm{B}, \mathrm{L}, \mathrm{TM}, \mathrm{S}, \mathrm{I}_{\mathrm{D}}\right.$, Ty $\}$. Table 2 defines and formalizes the properties that characterize the entity Sensor Node (Ni).

Table 2 - Definition of the properties of the entity Sensor Node $\left(\mathrm{N}_{\mathrm{i}}\right)$.

\begin{tabular}{|c|c|c|}
\hline 0 & Properties & Description / Formalization \\
\hline \multirow{6}{*}{ 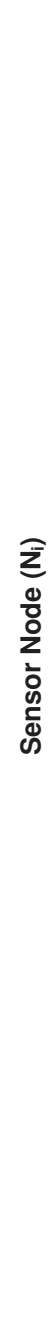 } & $\begin{array}{l}\text { Types of sensors } \\
\text { (TS) }\end{array}$ & $\begin{array}{l}\text { A sensor node }\left(\mathrm{N}_{\mathrm{i}}\right) \text { can have several types of sensors, each one measuring a } \\
\text { different phenomenon: Light }(\mathrm{Li}) \text {, Temperature }(\mathrm{Te}) \text {, Humidity }(\mathrm{Hu}) \text {, } \\
\text { Sound }(\mathrm{Sd}) \text {, Internal voltage }(\mathrm{Iv}), \text { Etc. } \\
\text { So, TS }\left(\mathrm{N}_{\mathrm{i}}\right) \subseteq\{\mathrm{Li}, \mathrm{Te}, \mathrm{Hu}, \mathrm{Sd}, \mathrm{Iv}, \ldots\}\end{array}$ \\
\hline & $\begin{array}{l}\text { Communication } \\
\text { modality (CM) }\end{array}$ & $\begin{array}{l}\text { A number of communication modalities can be used, such as: Radio (RF), } \\
\text { Light (Li), Ultrasound (US), Acoustical (Ac), Hybrid (Hy). } \\
\text { So, CM }\left(\mathrm{N}_{\mathrm{i}}\right) \subseteq\{\mathrm{RF}, \mathrm{Li}, \mathrm{US}, \mathrm{Ac}, \mathrm{Hy}\}\end{array}$ \\
\hline & $\begin{array}{l}\text { Transmission } \\
\text { Range (R) }\end{array}$ & $\begin{array}{l}\text { The nominal transmission range of a radio signal is typically a function of } \\
\text { its transmission power level }\left(\mathrm{P}_{\mathrm{t}}\right) \text {. Let } \mathrm{P}_{\mathrm{t}} \text { be the nominal transmission power } \\
\text { of a node. } \mathrm{P}_{\mathrm{R}} ; \mathrm{j} \leftarrow \mathrm{i} \text { is the received power of a signal propagated from node } \mathrm{i} \\
\text { to node } \mathrm{j} \text {. A received power } \mathrm{P}_{\mathrm{R}} ; \mathrm{j} \leftarrow \mathrm{i} \text { above a given threshold } \mathrm{P}_{\mathrm{t}} \text { will } \\
\text { provide sufficient } \mathrm{SNR} \text { (Signal to Noise Ratio) in the receiver to decode } \\
\text { the transmission. The nominal maximum distance for successful } \\
\text { communication can be defined as (Krohn et al., 2006): } \mathrm{R}=\mathrm{P}_{\mathrm{t}} / \mathrm{P}_{\mathrm{th}} \\
\text { Note that the range can vary between } r=(1-\varepsilon) . R \text { and } R, \varepsilon>0 \text {. }\end{array}$ \\
\hline & Battery (B) & $\begin{array}{l}\text { The lifetime of a sensor node }\left(\mathrm{N}_{\mathrm{i}}\right) \text { is limited by its battery, depending on its } \\
\text { capacity and type. The battery can be defined by: } \\
\text { Aype of battery }-\mathrm{T}_{\mathrm{B}} \text {, with } \mathrm{T}_{\mathrm{B}}\left(\mathrm{N}_{\mathrm{i}}\right) \in\{\text { lithium, alkaline, li-ion, } \\
\text { AA, external power supply, solar cells, electromagnetic and } \\
\text { piezoelectric transducers, etc. }\} \\
\text { Capacity (voltage) - } \mathrm{C}_{\mathrm{B}}\left(\mathrm{N}_{\mathrm{i}}\right)[\mathrm{V}] \\
\text { - Remaining capacity at time } \mathrm{t}_{\mathrm{j}}-\mathrm{P}_{\mathrm{BNi}}\left(\mathrm{t}_{\mathrm{j}}\right)[\%] \\
\mathrm{B}_{\mathrm{Ni}}\left(\mathrm{t}_{\mathrm{i}}\right)=\left\{\mathrm{T}_{\mathrm{B}}\left(\mathrm{N}_{\mathrm{i}}\right), \mathrm{C}_{\mathrm{B}}\left(\mathrm{N}_{\mathrm{i}}\right), \mathrm{P}_{\mathrm{BNi}}\left(\mathrm{t}_{\mathrm{j}}\right)\right\}\end{array}$ \\
\hline & Localization (L) & $\begin{array}{l}\text { Let } \mathrm{L}_{\mathrm{Ni}}\left(\mathrm{t}_{\mathrm{j}}\right) \text {, with } \mathrm{i} \in \mathcal{N} \text { and } \mathrm{j} \in \mathcal{T} \text {, denote the location of node } \mathrm{N}_{\mathrm{i}} \text { at time } \mathrm{t}_{\mathrm{j}} \text {. } \\
\text { The type of deployment affects important properties of the network (node } \\
\text { density, node locations, etc.). The deployment of sensor nodes may be: } \\
\text { this case, the localization of a node is unknown: } \\
\mathrm{L}_{\mathrm{Ni}}\left(\mathrm{t}_{\mathrm{j}}\right)=(\mathrm{x}, \mathrm{y}, \mathrm{z}) \text {, where } \mathrm{x}, \mathrm{y}, \mathrm{z} \in \mathbb{R} \text { are unknown. } \\
\text { Manual: sensor nodes are deployed in pre-determined positions. } \\
\text { In this case, the localization of a node is well-known: } \\
\mathrm{L}_{\mathrm{Ni}}\left(\mathrm{t}_{\mathrm{j}}\right)=(\mathrm{a}, \mathrm{b}, \mathrm{c}) \text {, where } \mathrm{a}, \mathrm{b}, \mathrm{c} \in \mathbb{R} \text { are known. }\end{array}$ \\
\hline & State $(\mathrm{S})$ & $\begin{array}{l}\text { Depending on its power mode, the node } \mathrm{N}_{\mathrm{i}} \text { can be in one of two states }(\mathrm{S}) \text { : } \\
\text { Active (Ac) - Node which is in the active state. } \\
\text { Inactive (In) - Node which is in the sleep mode, in order to save } \\
\text { energy. } \\
\text { So, } \mathrm{S}\left(\mathrm{N}_{\mathrm{i}}\right)=\mathrm{Ac} \text { or } \mathrm{S}\left(\mathrm{N}_{\mathrm{i}}\right)=\mathrm{In}\end{array}$ \\
\hline
\end{tabular}




\begin{tabular}{|c|c|c|}
\hline D & Properties & Description / Formalization \\
\hline & $\begin{array}{l}\text { Type of Mobility } \\
\text { (TM) }\end{array}$ & 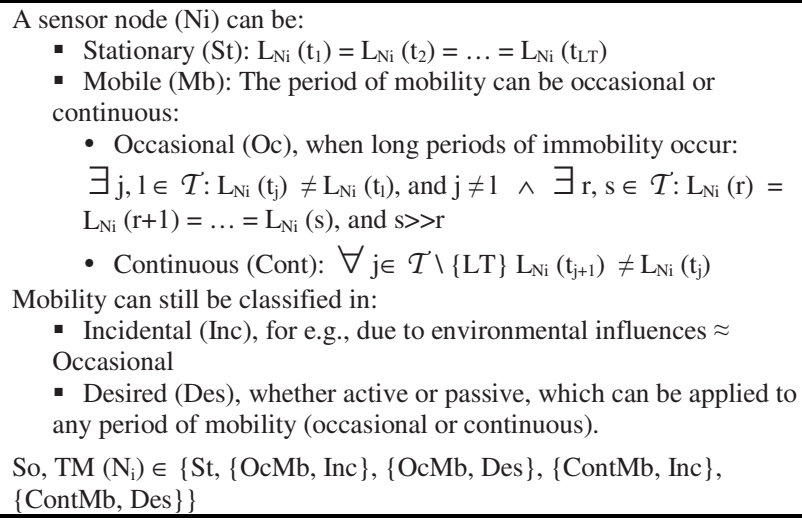 \\
\hline & Identifier ( $\left.\mathrm{I}_{\mathrm{D}}\right)$ & $\begin{array}{l}\text { Each sensor node has a unique identifier }\left(\mathrm{I}_{\mathrm{D}}\right) \\
\mathrm{I}_{\mathrm{D}}\left(\mathrm{N}_{\mathrm{i}}\right)=\mathrm{i}, \mathrm{i} \in \mathrm{N}\end{array}$ \\
\hline & Type (Тy) & $\begin{array}{l}\text { Alphanumeric that identifies the manufacturer and model of the sensor } \\
\text { node. } \\
\text { Ty }\left(\mathrm{N}_{\mathrm{i}}\right)=\left\{\text { Manufacturer }\left(\mathrm{N}_{\mathrm{i}}\right) \text {, Model }\left(\mathrm{N}_{\mathrm{i}}\right)\right\}\end{array}$ \\
\hline
\end{tabular}

Sink Node $\left(S_{K}\right)$

Only the properties that differentiate the sink node from the ordinary sensor nodes are described and formalized in Table 3, distinguishing between two cases: Stationary Sink Node $\left(\mathrm{StS}_{\mathrm{K}}\right)$ and Mobile Sink Node $\left(\mathrm{MbS}_{\mathrm{K}}\right)$.

Table 3 - Definition and formalization of some of the properties of the entity Sink Node $\left(S_{K}\right)$.

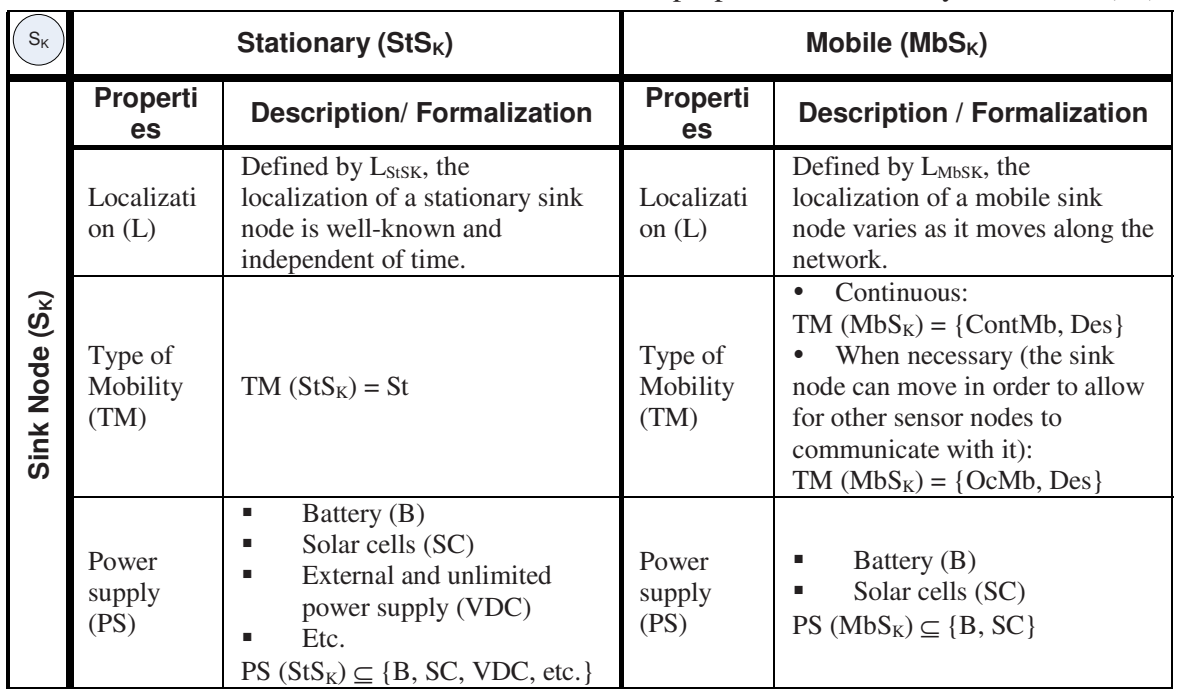

Network (WSN)

A WSN is defined by: WSN $=\left\{\right.$ To, M, H, Nr, A, C, D, Hi, NS $\left.\mathrm{K}_{\mathrm{K}}, \mathrm{NA}, \mathrm{LT}\right\}$. Table 4 defines and formalizes all the properties that characterize the entity Network (WSN). 
Table 4 - Definition of the properties of the entity Network (WSN).

\begin{tabular}{|c|c|c|}
\hline & Properties & Description / Formalization \\
\hline \multirow{11}{*}{ 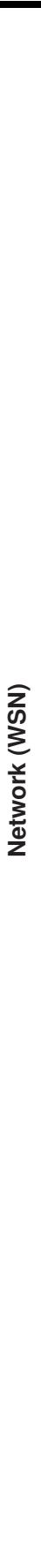 } & Topology (To) & $\begin{array}{l}\text { The WSN can have different topologies (To): Single-hop, Star, Networked } \\
\text { stars, Tree, Graph and Grid. } \\
\text { So, To } \in \text { SSingle-hop, Star, Net-Stars, Tree, Graph, Grid }\}\end{array}$ \\
\hline & Mobility (M) & $\begin{array}{l}\text { There are some different possible scenarios, regarding mobility of sensor } \\
\text { nodes: } \\
\text { - All nodes are stationary: } \forall \mathrm{i} \in \mathcal{N}, \forall \mathrm{j}, 1 € \mathcal{T} \mathrm{L}_{\mathrm{Ni}}\left(\mathrm{t}_{\mathrm{j}}\right)=\mathrm{L}_{\mathrm{Ni}}\left(\mathrm{t}_{1}\right) \\
\text { - } \\
\text { - } \text { Oll nodes are mobile: } \forall \mathrm{i} \in \mathcal{N}, \exists \mathrm{j}, 1 \in \mathcal{T} \text { : } \mathrm{L}_{\mathrm{Ni}}\left(\mathrm{t}_{\mathrm{j}}\right) \neq \mathrm{L}_{\mathrm{Ni}}\left(\mathrm{t}_{1}\right) \text {, and } \mathrm{j} \neq 1 \\
\text { Onome nodes move: } \\
\quad \exists \mathrm{i} \in \mathcal{N}, \exists \mathrm{j}, 1 \in \mathcal{T}: \mathrm{L}_{\mathrm{Ni}}\left(\mathrm{t}_{\mathrm{j}}\right) \neq \mathrm{L}_{\mathrm{Ni}}\left(\mathrm{t}_{1}\right) \text {, and } \mathrm{j} \neq 1 \wedge \exists \mathrm{p} \in \mathcal{N}: \mathrm{L}_{\mathrm{Np}}\left(\mathrm{t}_{1}\right)= \\
\\
\mathrm{L}_{\mathrm{Np}}\left(\mathrm{t}_{2}\right)=\ldots=\mathrm{L}_{\mathrm{Np}}\left(\mathrm{t}_{\mathrm{LT}}\right)\end{array}$ \\
\hline & $\begin{array}{l}\text { Homogeneity } \\
(\mathrm{H})\end{array}$ & $\begin{array}{l}\text { A WSN can be: } \\
\text { - Homogeneous }(\mathrm{Ho}) \text {, when it is composed by homogeneous devices, } \\
\text { which means that sensor nodes are mostly identical from a hardware and a } \\
\text { software point of view. } \\
\text { - Ho: } \forall \mathrm{i}, \mathrm{p} \in \mathcal{N}, \mathrm{Ty}\left(\mathrm{N}_{\mathrm{i}}\right)=\mathrm{Ty}\left(\mathrm{N}_{\mathrm{p}}\right) \text { and } \mathrm{i} \neq \mathrm{p} \\
\text { - Heterogeneous }(\mathrm{He}) \text {, when it is composed by heterogeneous devices, } \\
\text { which means that sensor nodes are mostly different from a hardware and a } \\
\text { software point of view, for e.g., in type and number of attached sensors } \\
\text { (TS). } \\
\text { - He: } \exists \mathrm{i}, \mathrm{p} \in \mathrm{N}: \mathrm{Ty}(\mathrm{Ni}) \neq \mathrm{Ty}(\mathrm{Np}) \\
\text { So, } \mathrm{H}=\mathrm{Ho} \text { or } \mathrm{H}=\mathrm{He}\end{array}$ \\
\hline & Number $(\mathrm{Nr})$ & $\begin{array}{l}\text { Total number of sensor nodes that constitute the WSN, which may vary } \\
\text { from a few nodes to thousands of sensor nodes. } \mathrm{Nr} \in \mathrm{N}\end{array}$ \\
\hline & Area (A) & Area of deployment $\left(\mathrm{m}^{2}\right) . \quad A \in \mathbb{R}^{+}$ \\
\hline & Coverage (C) & $\begin{array}{l}\text { A WSN can have different types of coverage: } \\
\text { - Sparse }(\mathrm{Sp}) \text {, when the network coverage is much smaller than its } \\
\text { deployment area. } \\
\text { - Dense (De), when the network coverage coincides with its deployment } \\
\text { area, or comes close to it. } \\
\text { - Redundant }(\mathrm{Re}) \text {, when multiple sensors cover the same area. } \\
\text { So, } \mathrm{C} \in\{\mathrm{Sp}, \mathrm{De}, \mathrm{Re}\}\end{array}$ \\
\hline & Density (D) & $\begin{array}{l}\text { Network density can be defined in terms of number of nodes per nominal } \\
\text { coverage area }(\text { Bulusu et al., } 2001) \text { : } \\
D=\left(N r \times \pi \times R^{2}\right) / C_{A} \text {, where } C_{A} \text { is the area that is covered by the whole } \\
\text { network. } C_{A}\left(m^{2}\right) \in \mathbb{R}^{+} \\
\text {Note that the coverage area }\left(C_{A}\right) \text { may be different from the deployment area } \\
\text { (A). }\end{array}$ \\
\hline & Hierarchy $(\mathrm{Hi})$ & $\begin{array}{l}\text { Clusters may be created according to: geographical area, type of sensor } \\
\text { nodes, type of phenomenon to monitor, etc., providing the WSN with a } \\
\text { hierarchical structure. } \\
\text { All clusters must have a cluster head (CH). }\end{array}$ \\
\hline & $\begin{array}{l}\text { Number of sink } \\
\text { nodes }\left(\mathrm{NS}_{\mathrm{K}}\right)\end{array}$ & $\begin{array}{l}\text { A WSN has one or more sink nodes. A sink node can be stationary }\left(\mathrm{StS}_{\mathrm{K}}\right) \\
\text { or mobile }\left(\mathrm{MbS}_{\mathrm{K}}\right) \text {. } \\
\mathrm{NS}_{\mathrm{K}}<\mathrm{Nr}\end{array}$ \\
\hline & $\begin{array}{l}\text { Number of } \\
\text { anchor nodes } \\
\text { (NA) }\end{array}$ & $\begin{array}{l}\text { Anchor nodes are nodes with known location. They can be stationary or } \\
\text { mobile: } \\
\text { - Stationary anchor node (StA) } \\
\text { - Mobile anchor node (MbA) } \\
\mathrm{NA}<\mathrm{Nr}\end{array}$ \\
\hline & Lifetime (LT) & $\begin{array}{l}\text { Deployment may be: } \\
\text { - One-time activity. In this case, } \mathrm{LT}=\mathrm{K} \text { with } \mathrm{K} \in \mathbb{N}\end{array}$ \\
\hline
\end{tabular}




\begin{tabular}{|l|l|l|}
\hline & Properties & Description / Formalization \\
\hline & & - Iterative (continuous) process. In this case, LT $\approx \infty$ \\
\hline
\end{tabular}

\subsection{Example Scenario}

We validate the WSNSCW model by applying it to the specific case of an environmental monitoring application. This work was developed in the context of an European project, named FORESMAC (Project INTERREG III B, 05/MAC/2.3/C16). The purpose of this project is to create a WSN in order to accomplish environmental monitoring of forests.

So, let's consider the example of a forest monitoring WSN. As Figure 1 illustrates, there are 3 simultaneous collaborative sessions. These sessions where initiated by the user, with three different objectives: to monitor the temperature of area A1 (CS1), to monitor the light of area A2 (CS2), and to monitor the humidity of the same area (CS3). So, nodes were deployed in an ad hoc manner, in two different geographical areas of a forest CS2 and CS3 represent exactly the same area; hence, exactly the same nodes). There are 2 sink nodes, 4 anchor nodes and 20 wireless sensor nodes. Within each area, clusters have been created; there are 2 clusters in Area A1 and 2 clusters in area A2; hence, there are 4 cluster heads $(\mathrm{CH})$.

As this scenario relates to an environmental monitoring application, it is very important to correlate collected data in space. So, anchor nodes had to be deployed. The nodes that belong to a cluster are in the active state, as they need to monitor the phenomenon. The remaining nodes are in the sleep mode. The user is typically far away from the forest being monitored. So, he monitors it through the Internet.

Any changes that might occur on this scenario (new collaborative sessions, new clusters, nodes changing from sleep mode to the active state or vice versa, nodes moving, etc.) can be represented by a sequence of figures analogous to Figure 1.

So, by using the WSNSCW model to represent a WSN, it is possible to easily identify the different components of the network and its operation.

\subsection{Awareness Tool}

We are developing a 3D awareness tool, based in the WSNSCW model that will allow for an interactive navigation in the map of the network. The 3D representation of the network is very important for an awareness tool, so the user can have a more realistic view of the network; it is more appropriated for representing a WSN deployed in different types of terrains (flat, mountainous, etc.), different types of rooms, which obstacles might interfere with the collaboration established between nodes, etc.

Besides allowing for the visualization of all the components defined in the model (different types of nodes, relationships between them, different clusters, data flows, etc.) and its properties, this tool will allow for the visualization of the network hierarchy and, also, for the visualization of different granularities: fine-grain (sensor nodes), middle-grain (clusters) and coarser (sessions) modeling level. 


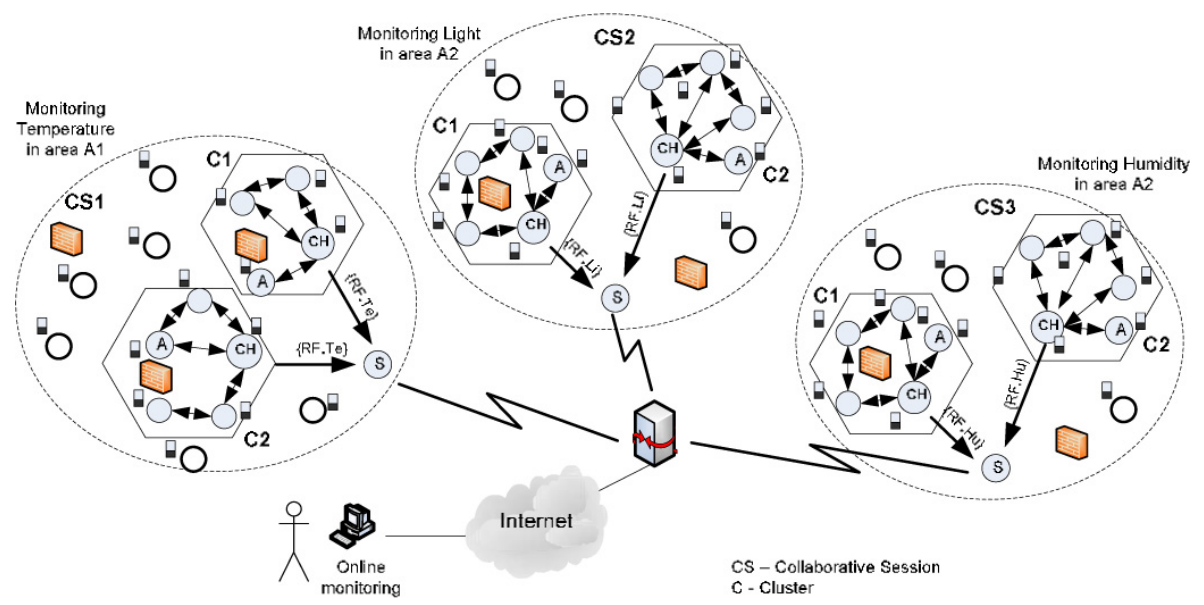

Figure 1 - Applying the WSNSCW model to the specific case of a forest environmental monitoring.

\section{CONCLUSIONS AND FUTURE WORK}

In this paper we presented the WSNSCW model, which is based in the CSCW methodology and specifically designed for WSNs. The great advantage of this model lies in the fact that, besides modelling collaboration, it also allows for modelling the entire WSN, all its entities, properties, relationships, states, etc., which is fundamental to completely represent a WSN.

This model allows for the representation of the network hierarchy (from the collected data to the user), as well. Moreover, it allows for the representation of each state of the network and its evolution.

In this paper, we applied this model to the specific case of a forest environmental monitoring application. However, it is a generic model that can be applied to an heterogeneous network (any type of sensors and any type of application). So, it is possible to use the entities defined in the model to represent a certain scenario of any application (monitoring a forest, a vineyard, a volcano, a museum, etc.).

Regarding collaboration, the model includes some CSCW concepts (such as: session, relationship, data flow and groups) and properties (such as: connectivity and flow control). In the near future, we intend to include more CSCW concepts. We also intend to complete the formalization of this model using graph theory.

The WSNSCW model is being used as a basis for the development of a 3D awareness tool, which aims at giving the user a more realistic view of the network. 


\section{REFERENCES}

1. Akyildiz, I., Su, W., Sankarasubramaniam, Y., Cayirci, E., "A Survey on Sensor Networks", IEEE Communications Magazine, Aug. 2002, pp. 102-109.

2. Bulusu, N., Estrin, D., Girod, L., Heidemann, J., "Scalable Coordination for Wireless Sensor Networks: Self-Configuring Localization Systems", Proc. of the 6th International Symposium on Communication Theory and Applications (ISCTA'01), Ambleside, UK, July 2001, pp. 1-6.

3. Bychkovskiy, V., Megerian, S., Estrin, D., Potkonjak, M., "A Collaborative Approach to In-Place Sensor Calibration", 2nd International Workshop on Information Processing in Sensor Networks (IPSN'03), April 2003.

4. Chadha, A., Liu, Y., Das, S., "Group Key Distribution via Local Collaboration in Wireless Sensor Networks", 2nd Annual IEEE Communications Society Conference on Sensor and Ad Hoc Communications and Networks (SECON 2005), Santa Clara, California, USA, Sep. 2005.

5. Chen, G., Guo, T.-D., Yang, W.-G., Zhao, T., "An improved ant-based routing protocol in Wireless Sensor Networks", International Conference on Collaborative Computing: Networking, Applications and Worksharing (CollaborateCom 2006), Nov. 2006, pp. 1-7.

6. Cheng, L., Lian, T., Zhang, Y., Ye, Q., "Monitoring Wireless Sensor Networks by Heterogeneous Collaborative Groupware", Sensors for Industry Conference (Sicon/04), New Orleans, USA, Jan. 2004.

7. Dardari, D., Conti, A., "A Sub-Optimal Hierarchical Maximum Likelihood Algorithm for Collaborative Localization in Ad-Hoc Networks", 1st Annual IEEE Communications Society Conference on Sensor and Ad Hoc Communications and Networks (IEEE SECON 2004), Oct. 2004, pp. 425- 429.

8. Giannecchini, S., Caccamo, M., Shih, C.-S., "Collaborative resource allocation in wireless sensor networks", in Proc. of Euromicro Conference on Real-Time Systems (ECRTS'04), June/July 2004, pp. 35-44.

9. Gracanin, D., Adams, K., Eltoweissy, M., "Data Replication in Collaborative Sensor Network Systems", in Proc. 25th IEEE International Performance, Computing, and Communications Conference (IPCCC 2006), April 2006, pp. 389-396.

10. Hu, A., Servetto, S., "Algorithmic Aspects of the Time Synchronization Problem in Large-Scale Sensor Networks", Mobile Networks and Applications, 10, 2005 Springer Science + Business Media Inc., 2005, pp. 491-503.

11. Iftode, L., Borcea, C., Kang, P., Cooperative Computing in Sensor Networks, Handbook of Sensor Networks: Compact Wireless and Wired Sensing Systems, Mohammad Ilyas (ed.), CRC Press, July 2004.

12. Krohn, A., Beigl, M., Decker, C., Riedel, T., Zimmer, T., Varona, D., "Increasing Connectivity in Wireless Sensor Network using Cooperative Transmission", 3rd International Conference on Networked Sensing Systems (INSS), Chicago, USA, May/June, 2006.

13. Liu, L., Ma, H., Tao, D., Zhang, D., "A Hierarchical Cooperation Model for Sensor Networks Supported Cooperative Work", in Proc. of 10th International Conference on Computer Supported Cooperative Work in Design (CSCWD'06), May 2006, pp. 1-6.

14. Ramanathan, P., Saluja, k., Hu, Y., "Collaborative Sensor Signal Processing for Target Detection, Localization and Tracking", in Proc. of 23rd Army Science Conference, Dec. 2002.

15. Reghelin, R., Fröhlich, A., "A Decentralized Location System for Sensor Networks Using Cooperative Calibration and Heuristics", in Proc. of 9th ACM international symposium on Modeling Analysis and Simulation of Wireless and Mobile Systems (MSWiM'06), Torremolinos, Spain, 2006, pp. 139-146.

16. Sanli, H., Poornachandran, R., Cam, H., "Collaborative Two-Level Task Scheduling for Wireless Sensor Nodes", in Proc. of IEEE Communications Society Conference on Sensor and Ad Hoc Communications and Networks (SECON 2005), Santa Clara, USA, Sept. 2005.

17. Wang, K.-C., Ramanathan, P., "Collaborative Sensing Using Sensors of Uncoordinated Mobility", International Conference on Distributed Computing in Sensor Systems (Lecture Notes in Computer Science), Marina del Rey, USA, June 2005, pp. 293-306. 